\title{
Multi-Class Logit Regression Model Analysis of the Fertility Willingness of Two Children in Hunan Province under the Comprehensive Two-Child Policy
}

\author{
Lujun Zhou ${ }^{1,2}$ \\ ${ }^{1}$ School of Information and Statistics, Guangxi University of Finance and Economics, Nanning, China \\ ${ }^{2}$ Economic College, Hunan Agricultural University, Changsha, China \\ Email: davi44049895@163.com
}

How to cite this paper: Zhou, L. J. (2019). Multi-Class Logit Regression Model Analysis of the Fertility Willingness of Two Children in Hunan Province under the Comprehensive Two-Child Policy. Chinese Studies, 8, 175-183.

https://doi.org/10.4236/chnstd.2019.84014

Received: October 4, 2019

Accepted: November 18, 2019

Published: November 21, 2019

Copyright ( 2019 by author(s) and Scientific Research Publishing Inc. This work is licensed under the Creative Commons Attribution International License (CC BY 4.0).

http://creativecommons.org/licenses/by/4.0/

\begin{abstract}
Based on the "Residents' Willingness and Policy Improvement" questionnaire survey data of 394 families in Hunan Province in 2017, this study compared the family's two-child fertility willingness, and used the multi-category logit model to explore the factors affecting the family's second-child fertility willingness under the comprehensive two-child policy. The factors related to the family's second child's willingness to give birth under the two-child policy. The study found that: 1) age, the nature of the work unit, marital status, children's attitude, the attitude of the elderly, the care of the two children, and the physical condition of the parents, real estate, loans, the level of consumption, and security variable have a certain degree of influence on the fertility willingness. 2) Variables such as gender, household registration, number of dependent elderly, and financial support of parents have no significant influence on fertility willingness.
\end{abstract}

\section{Keywords \\ Universal Two-Child Policy, Fertility Willingness, "Four-Dimensional" Characteristics, Multi-Class Logit Model}

\section{Open Access}

\section{Introduction}

Since the Family Planning was determined as a basic national policy in 1982, the speed of population growth has been effectively controlled, and the pressure brought by population growth to the resource environment has been alleviated, and the size of households has been shrinking. In 2013, the Third Plenary Ses- 
sion of the 18th CPC Central Committee decided to launch the "Separate Two Children" policy. In October 2015, the Fifth Plenary Session of the 18th CPC Central Committee decided to adhere to the basic national policy of family planning, improve the population development strategy, fully implement the policy of a couple of children to have two children, and actively carry out the action against population aging.

Yang \& Wang (2015) conducted a sample survey on the intentional survey of a single second child of the childbearing age group in Qinghe Community of Hangzhou, using the two categorical variables of "whether there is a willingness to have a second child" as the dependent variable for multi-factor unconditional Logistic regression analysis, economic conditions, occupation, education, gender and environmental factors have a certain impact on the second child's will.

Zeng (2015) pointed out that the implementation of the "universal permission for two children" policy in urban and rural areas as soon as possible will benefit both the country and the people. Ran et al. (2015) obtained the factors affecting the fertility willingness through the analysis of micro survey data. The results show that the comprehensive liberalization of the second child policy will gradually increase the future population and maintain a relatively stable level. It is recommended that the country releases the birth policy in a timely manner. Dan Zhang (2015) conducted an economic analysis of the factors affecting the fertility willingness of Xi'an citizens after the implementation of the comprehensive two-child policy, and found that economic factors mainly affect the fertility willingness.

The variable value of the dependent variable of this research paper is divided into three values: "willing, unwilling, and uncertain". The multi-class logit model will be used to analyze the factors affecting fertility willingness.

\section{Basic Conditions of Fertility Willingness}

\subsection{Objects and Methods}

\subsubsection{Survey Object}

Under the "Comprehensive Two-Child" policy, 20 - 50 years old childbearing age group with only one child in Hunan Province was investigated. Through the sampling method of convenient sampling, the fertility willingness survey was carried out from four aspects: personal characteristics, family characteristics, economic characteristics and social characteristics.

\subsubsection{Survey Method}

This study mainly uses the questionnaire survey method: in order to understand the response of the comprehensive two-child policy, based on the full reading of the literature, the questionnaire on the fertility willingness after the implementation of the "Comprehensive Two-Child" policy in Hunan Province was designed, and consulted with economics. Experts such as statistics and management have revised the questionnaire several times to form the final version of the questionnaire. The questionnaire has a total of 48 questions, covering basic in- 
formation about individual families and factors affecting fertility willingness. The influencing factors of fertility willingness are carried out from four dimensions: personal characteristics, family characteristics, economic characteristics and social characteristics. Personal characteristics dimensions include gender, age, education level, marital status, household registration and job nature; family characteristics dimensions include factors such as child gender, child age, spouse basic information, parental care attitude, etc.; economic characteristics dimensions include family purchase assets, economy Levels, consumption levels, child expenditure levels, parental care expenditure levels, etc.; social characteristics dimensions include the expected gender of the two children, the positive and negative effects of the two children on the first child (multiple choice questions), and the motivations and obstacles of the birth of the two children (Multi-choice questions), "five insurance and one housing fund" security and other factors. The questionnaire was distributed using a combination of field survey questionnaires. A total of 500 questionnaires were distributed, and 106 invalid questionnaires (non-Hunan Province, many missing values, poor consistency, high repetition rate) were excluded, and 394 were fully valid questionnaires, with an effective rate of $78.8 \%$.

\subsubsection{Statistical Methods}

This paper uses spss software to describe the effective questionnaire and multi-class logit regression model analysis.

\subsection{General Situation of the Sample}

Among the 394 respondents surveyed, $32.5 \%$ were willing to give birth, $41.9 \%$ were unwilling to give birth, and $25.6 \%$ were determined; 142 were males, $36 \%$ were females, and 252 were females, accounting for $64 \%$; The age is mainly from 20 to 50 years old; the degree is mainly junior college/undergraduate, accounting for $38.3 \%$; the marital status is mainly based on the first marriage, accounting for $79.2 \%$ (see Table 1).

Table 1. General situation of the sample $(\mathrm{n}=394)$.

\begin{tabular}{clcc}
\hline \multicolumn{1}{c}{ Variable } & \multicolumn{1}{c}{ Variable value } & Frequency & Proportion \\
\hline \multirow{3}{*}{ Fertility willingness } & 1) willing & 128 & $32.50 \%$ \\
& 2) unwilling & 165 & $41.90 \%$ \\
& 3) uncertain & 101 & $25.60 \%$ \\
& 1) male & 142 & $36.00 \%$ \\
Gender & 2) Female & 252 & $64.00 \%$ \\
& 1) junior high school and below & 59 & $15.00 \%$ \\
Education level & 2) high school/secondary school & 130 & $33.00 \%$ \\
& 3) junior college/undergraduate & 151 & $38.30 \%$ \\
& 4) graduate students and above & 54 & $13.70 \%$ \\
Household registration & 1) agriculture & 136 & $34.50 \%$ \\
& 2) non-agricultural & 258 & $65.50 \%$ \\
\hline
\end{tabular}




\section{Continued}

\begin{tabular}{|c|c|c|c|}
\hline \multirow{3}{*}{ Marital status } & 1) first marriage and residence & 312 & $79.20 \%$ \\
\hline & 2) first marriage, Non-inhabited & 62 & $15.70 \%$ \\
\hline & 3) remarriage & 20 & $5.10 \%$ \\
\hline \multirow{5}{*}{ Unit character } & $\begin{array}{l}\text { 1) state-owned enterprises and } \\
\text { institutions, civil servants }\end{array}$ & 129 & $32.70 \%$ \\
\hline & 2) joint ventures, foreign companies & 41 & $10.40 \%$ \\
\hline & 3) private enterprises, individual owners & 151 & $38.30 \%$ \\
\hline & 4) farming & 26 & $6.60 \%$ \\
\hline & 5) unemployed & 47 & $11.90 \%$ \\
\hline \multirow{2}{*}{ Child gender } & 1) boy & 209 & $53.00 \%$ \\
\hline & 2) girl & 185 & $47.00 \%$ \\
\hline \multirow{4}{*}{$\begin{array}{l}\text { Child attitude towards two } \\
\text { children }\end{array}$} & 1) support & 81 & $20.60 \%$ \\
\hline & 2) does not matter & 243 & $61.70 \%$ \\
\hline & 3) against & 70 & $17.80 \%$ \\
\hline & 1) 1 & 18 & $4.60 \%$ \\
\hline \multirow[t]{2}{*}{ Number of elderly people } & 2) 2 & 76 & $19.30 \%$ \\
\hline & 3) 3 and above & 300 & $76.10 \%$ \\
\hline \multirow{3}{*}{$\begin{array}{l}\text { Parental attitude towards two } \\
\text { children }\end{array}$} & 1) support & 126 & $32.00 \%$ \\
\hline & 2) does not matter & 230 & $58.40 \%$ \\
\hline & 3) against & 38 & $9.60 \%$ \\
\hline \multirow{3}{*}{ Two-child care } & 1) child's grandparents & 127 & $32.20 \%$ \\
\hline & 2) own & 232 & $58.90 \%$ \\
\hline & 3) other people & 35 & $8.90 \%$ \\
\hline \multirow{4}{*}{$\begin{array}{l}\text { Number of brothers and } \\
\text { sisters }\end{array}$} & 1) none & 57 & $14.50 \%$ \\
\hline & 2) 1 & 80 & $20.30 \%$ \\
\hline & 3) 2 & 142 & $36.00 \%$ \\
\hline & 4) 3 and above & 115 & $29.20 \%$ \\
\hline \multirow{3}{*}{ Father's physical condition } & 1) very good & 66 & $16.80 \%$ \\
\hline & 2) good & 136 & $34.50 \%$ \\
\hline & 3) general and bad & 192 & $48.70 \%$ \\
\hline \multirow{3}{*}{ Mother's physical condition } & 1) very good & 64 & $16.20 \%$ \\
\hline & 2) good & 129 & $32.70 \%$ \\
\hline & 3) general and bad & 201 & $51.00 \%$ \\
\hline \multirow{2}{*}{ Is there a housing? } & 1) Yes & 292 & $74.10 \%$ \\
\hline & 2) no & 102 & $25.90 \%$ \\
\hline \multirow{2}{*}{ Does the family have a loan? } & 1) Yes & 203 & $51.50 \%$ \\
\hline & 2) no & 191 & $48.50 \%$ \\
\hline \multirow{3}{*}{$\begin{array}{l}\text { Do you have five insurances } \\
\text { and housing fund? }\end{array}$} & 1) Yes & 238 & $60.40 \%$ \\
\hline & 2) no & 156 & $39.60 \%$ \\
\hline & 1) less than 50,000 & 147 & $37.30 \%$ \\
\hline \multirow{2}{*}{$\begin{array}{l}\text { Total annual household } \\
\text { consumption (RMB yuan) }\end{array}$} & 2) $50,000-100,000$ & 177 & $44.90 \%$ \\
\hline & 3) more than 100,000 & 70 & $17.80 \%$ \\
\hline \multirow{2}{*}{$\begin{array}{l}\text { Whether parents provide } \\
\text { financial support }\end{array}$} & 1) yes & 182 & $46.20 \%$ \\
\hline & 2) no & 212 & $53.80 \%$ \\
\hline
\end{tabular}




\section{Empirical Models and Results Analysis}

\subsection{Empirical Model}

In order to consider the influence of the family's two-child fertility willingness, since the explanatory variable is whether the respondent intends to give birth to two children (willing, unwilling, uncertain), the two multi-class Logit models are established and the estimated results are shown in Table 2.

Table 2. Estimation results of logit models of fertility willingness.

\begin{tabular}{|c|c|c|c|c|c|c|}
\hline \multirow[b]{2}{*}{ Variable } & \multicolumn{3}{|c|}{ Willing versus unwilling model I } & \multicolumn{3}{|c|}{ Uncertain versus unwilling model II } \\
\hline & coefficient & significance & $\operatorname{Exp}(B)$ & coefficient & significance & $\operatorname{Exp}(B)$ \\
\hline intercept & 3.952 & 0.044 & & 7.570 & 0.000 & \\
\hline age & -0.116 & 0.001 & 0.891 & -0.183 & 0.000 & 0.833 \\
\hline [gender $=1$ ] & 0.310 & 0.361 & 1.364 & -0.127 & 0.717 & 0.881 \\
\hline [edu level = 1] & -0.043 & 0.950 & 0.958 & -0.795 & 0.254 & 0.452 \\
\hline [edu level = 2] & 0.561 & 0.323 & 1.752 & -0.044 & 0.939 & 0.957 \\
\hline [edu level = 3] & 0.098 & 0.844 & 1.103 & -0.231 & 0.633 & 0.794 \\
\hline$[$ Household registration $=1]$ & 0.481 & 0.210 & 1.617 & 0.136 & 0.730 & 1.145 \\
\hline$[$ Marital status $=1]$ & -1.307 & 0.073 & 0.271 & 0.267 & 0.762 & 1.306 \\
\hline$[$ Marital status $=2]$ & -1.359 & 0.085 & 0.257 & -0.058 & 0.951 & 0.944 \\
\hline [unit character $=1$ ] & 1.354 & 0.038 & 3.872 & 0.541 & 0.365 & 1.718 \\
\hline [unit character $=2$ ] & 0.731 & 0.318 & 2.077 & -1.138 & 0.135 & 0.321 \\
\hline [unit character $=3$ ] & -0.016 & 0.978 & 0.984 & -0.651 & 0.220 & 0.522 \\
\hline [unit character $=4]$ & 1.344 & 0.118 & 3.834 & 0.734 & 0.396 & 2.083 \\
\hline$[$ Child gender $=1]$ & 0.314 & 0.325 & 1.369 & 0.031 & 0.923 & 1.031 \\
\hline [Child attitude $=1$ ] & 1.931 & 0.000 & 6.894 & 0.819 & 0.137 & 2.269 \\
\hline [Child attitude $=2$ ] & 0.762 & 0.089 & 2.142 & 0.403 & 0.333 & 1.497 \\
\hline [Number of elderly people $=1$ ] & 0.885 & 0.251 & 2.423 & 1.347 & 0.080 & 3.848 \\
\hline [Number of elderly people $=2$ ] & 0.151 & 0.702 & 1.163 & 0.104 & 0.809 & 1.110 \\
\hline$[$ Parental attitude $=1]$ & 1.181 & 0.052 & 3.257 & 0.580 & 0.322 & 1.787 \\
\hline$[$ Parental attitude $=2]$ & -0.446 & 0.431 & 0.640 & -0.855 & 0.109 & 0.425 \\
\hline [Two-child care $=1]$ & -1.149 & 0.076 & 0.317 & -1.470 & 0.015 & 0.230 \\
\hline$[$ Two-child care $=2]$ & 0.145 & 0.814 & 1.156 & -1.234 & 0.036 & 0.291 \\
\hline$[$ Number of bros and sis $=1]$ & 0.983 & 0.070 & 2.674 & -0.246 & 0.658 & 0.782 \\
\hline [Number of bros and sis $=2$ ] & 0.711 & 0.148 & 2.035 & -0.158 & 0.750 & 0.854 \\
\hline [Number of bros and sis $=3$ ] & 1.238 & 0.003 & 3.447 & 0.732 & 0.068 & 2.078 \\
\hline [Father's physical = 1] & -1.051 & 0.098 & 0.349 & -1.235 & 0.055 & 0.291 \\
\hline [Father's physical = 2] & -0.225 & 0.610 & 0.798 & -0.730 & 0.100 & 0.482 \\
\hline$[$ Mother's physical = 1] & 1.143 & 0.075 & 3.138 & 0.304 & 0.654 & 1.355 \\
\hline [Mother's physical = 2] & 0.420 & 0.352 & 1.521 & 0.120 & 0.788 & 1.127 \\
\hline
\end{tabular}




\section{Continued}

\begin{tabular}{ccccccc}
\hline [housing = 1] & -0.515 & 0.211 & 0.597 & 0.882 & 0.052 & 2.415 \\
[loan = 1] & 0.092 & 0.786 & 1.096 & 0.548 & 0.098 & 1.729 \\
[five insurances and fund = 1] & -0.716 & 0.066 & 0.489 & -0.900 & 0.021 & 0.407 \\
[TA household cons = 1] & -1.278 & 0.008 & 0.279 & -0.758 & 0.129 & 0.469 \\
[TA household cons = 2] & -0.858 & 0.048 & 0.424 & -0.441 & 0.321 & 0.644 \\
[parents' financial support = 1] & -0.090 & 0.793 & 0.914 & -0.187 & 0.586 & 0.829 \\
\hline
\end{tabular}

Note: Each categorical variable is referenced to the highest value of each variable in the regression.

\subsection{Results and Analysis}

From Table 2, we obtained that:

\subsubsection{Personal Characteristics Variables: Age, Gender, Education Level, Household Registration, Unit Nature}

In terms of age, there is a significant difference at $1 \%$ significance level in the both models between being born versus not being born, and being uncertain versus not living. Since the coefficient corresponding to the age variable is negative, the greater willingness to be unwilling to give birth as we get older. Gender differences in the two models are not significant, indicating that men and women in the family have a consistent opinion. In terms of the level of education, no matter what level of education, there is no significant difference in the willingness to show birth. In the household registration, the two models also showed inconspicuousness. In terms of the unit nature, the state-owned enterprises and institutions and civil servants in the first model showed significant differences at $5 \%$ significance level compared with the others. This group was suppressed by fertility before the second child policy. After the two-child policy was liberalized, the families of state-owned enterprises, civil servants and so on would welcome the birth of two children. The other households have basically no influence.

\subsubsection{Family Characteristics Variables: Marital Status, Child Characteristics, Number of Dependent Elderly, Attitudes of Children and the Elderly to Two Children, Care of Two Children, Physical Condition of Parents}

In terms of marital status in model $\mathrm{I}$, the first-married family is significantly different from the remarried family at the $10 \%$ significance level, and will be more willing to have two children. In families with uncertain fertility intentions in model II, the difference in marital status is not significant. In the first child gender, the two models are not significant, indicating that the gender of the first child does not affect the willingness to give birth. The fertility will not be significantly affected in the number of elderly people. In the children's attitude towards the two children, the first model showed great significance at $1 \%$ and $10 \%$ significance level. The more the child actively asked the younger brother and younger sister, the stronger the willingness of parents to have two children. In the uncertain model II, the child has basically no influence on the attitude of the two 
children. In the attitude of the elderly to the two children, the first model showed significant differences at $10 \%$ significance level, and the proactive request would be more conducive to the birth of two children. In the care of the birth of the second child, the child's grandparents are actively asked to bring the children, which will also benefit the birth of two children. In the second model, the grandparents' time to take care of the two children will increase uncertainty versus unwilling and become more willing to get birth. In the same way, the better the physical condition of the parents, the more likely the family will have two children.

\subsubsection{Economic Characteristics Variables: Real Estate, Loans, Total Annual Household Consumption, Parental Economic Support}

In the two variables of real estate and family loans, the first model showed consistent behavior, indicating that real estate and family loans did not affect the willingness to have children. Instead, in the model II, the two variables of real estate and loans showed significant differences at $10 \%$ significance level. More real estate and loans would increase uncertainty. In the total annual household consumption variable, the first model showed significant difference at $1 \%$ and $5 \%$ significance level and the coefficients are negative. The more the households consumed, the lower the behavior of family fertility willingness. While there was no significant difference in the second model. Both models did not show significant difference in parental financial support.

\subsubsection{Social Characteristics Variables: Social Security}

In the social security variable, both models showed significant difference. If there are social security such as five insurances and one housing fund, the family will increase the willingness to give birth from unwillingness to give birth in model I and will also increase the probability of families who are unwilling to give birth to families with uncertain births in model II.

\section{Conclusion, Countermeasures, Prospects}

The research results indicate that the variables, such as age, the nature of the work unit, marital status, children's attitude, the attitude of the elderly, the care of the two children, and the physical condition of the parents, real estate, loans, the level of economic consumption, and security variable, have a certain degree of significant influence on the fertility willingness.

The "Comprehensive Two-Child" policy was introduced to conform to the laws governing the development of China's population and to improve the structure of population development. It is the need of social and economic development and the need to fully realize the great rejuvenation goal of the Chinese nation. According to the relevant conclusions drawn from the factors affecting the fertility willingness of residents in Hunan Province, corresponding countermeasures and suggestions can be provided from both the government and the family: 
1) Strengthen publicity and create a fertility-friendly society

It is known from the analysis conclusion that the fertility willingness is affected by the family as a whole. The nature of the work unit, the level of economic consumption, the care of the two children, the support of the children and parents to the two children, and the physical condition of the parents all have a certain degree of influence on the fertility willingness. The government should raise the level of public services, vigorously promote the "two-child comprehensive" policy, and let the family publicize the policy dividends from the aspects of family pension and family structure stability, encourage families to bear children, and promote the childbearing willingness of the two children.

2) Establish and improve the social service security system

The government establishes and improves the medical security system, establishes market access for care services, develops a set of service standards, and improves maternity-related services so that the masses can enjoy the services with confidence and at the same time alleviate the care pressure of the reborn families. At the same time, the government should properly extend maternity leave during pregnancy to allow women to have sufficient time to recover and care for the health of the newborn. The government should also introduce a policy to encourage the birth of two children, provide tax incentives for the two-child family, and appropriate subsidies for the two-child family to reduce the financial burden of the two-child family. The government establishes and improves the social endowment insurance system, and at the same time improves the maternity insurance system, increases the state's financial input, and subsidizes insurance funds.

Although this survey has obtained some useful conclusions, there are many deficiencies and limitations, such as not considering the influence of the spouse-related variables. In the later studies, we would consider the fertility behavior of the two children and its influencing factors. If we continue to follow up on the families surveyed in the previous survey, we can further analyze the differences between family fertility willingness and behavior and its influencing factors.

\section{Funding}

This paper is supported by Hunan Natural Science Fund Project (2017JJ2114), Hunan Provincial Social Science Fund Project (16YBA204).

\section{Conflicts of Interest}

The author declares no conflicts of interest regarding the publication of this paper.

\section{References}

Yang, Y. L., \& Wang, Y. (2015). The Investigation of the Intention of "Separate Second Child" in Qinghe Community of Hangzhou City and Its Influencing Factors. Intelligence, No. 34. (Chinese Version) 
Zeng, Y. (2015). Implementing the Universal Two-Child Policy as Soon as Possible Is a Win-Win Policy for Both the Nation and the People. Population Economics, No. 5. (Chinese Version)

Ran, Y. J. et al. (2015). Population Prediction Based on Fertility Willingness under the Change of Population Policy. (4th) National College Student Statistical Modeling Competition Paper, 2015-11-29 (Chinese Version)

Zhang, D. (2015). Economic Analysis of the Influencing Factors of Xi'an Citizens' Fertility Willingness after the Implementation of the Comprehensive Two-Child Policy. Labor Security World, No. 26. (Chinese Version) 